\title{
Distance effects on patterns and processes of dispersal in an octocoral-associated amphipod
}

\author{
Naoki H. Kumagai* \\ Shimoda Marine Research Center, University of Tsukuba, 5-10-1 Shimoda, Shizuoka 415-0025, Japan \\ Present address: Graduate School of Science and Technology, Chiba University, 1-33 Inage, Chiba 263-8522, Japan
}

\begin{abstract}
Similar to pelagic larval dispersal, it has been suggested that dispersal of post-larval benthic organisms and species with direct development plays an important role in population persistence. However, effective dispersal distances required for the maintenance of local populations have been poorly characterized. This study elucidated distance effects on patterns and processes in dispersal of the amphipod Incisocalliope symbioticus, which is associated exclusively with the gorgonian octocoral Melithaea flabellifera. Dispersal patterns over an annual cycle were examined by the placement of defaunated gorgonians at 3 distance levels $(<0.2,8,70 \mathrm{~m})$ for $1 \mathrm{wk}$. With an increase in distance from the source population, the dispersal rate decreased; conversely, the proportion of females and large individuals increased. This result suggested that colonizers that dispersed over long distances had the potential for rapid establishment of breeding aggregations, and therefore were responsible for the maintenance of local populations. Furthermore, the short-distance dispersal within a local population was dependent on the density of the resident population, whereas middleand long-distance dispersal resulted from density-independent passive transport, driven by typhoon and storm events. Results of direct observations on the movements of live and, as a control, dead amphipods toward a gorgonian patch in the field showed that the amphipods had sufficient swimming ability $\left(3.4 \mathrm{~m} \mathrm{~min}^{-1}\right.$ ) for short-distance dispersal, and actively selected to move toward the patch. These results indicated that the combination of passive transport and the active selection enables the amphipod to migrate over long distances among local populations, even though the habitat of the amphipod only occurs sporadically.
\end{abstract}

KEY WORDS: Population persistence $\cdot$ Direct development $\cdot$ Host specialization $\cdot$ Storm $\cdot$ Gorgonian Resale or republication not permitted without written consent of the publisher

\section{INTRODUCTION}

Dispersal is an important process that can regulate local and regional population persistence. Effects of dispersal on population persistence are particularly important in marine organisms, because many of them disperse over a long distance during pelagic larval stages (Underwood \& Fairweather 1989). On the other hand, post-larval benthic organisms and species with direct development have long been thought to be restricted in dispersal ability required to maintain local populations. Recently, dispersal patterns and processes of post-larval benthic organisms and species with direct development have been studied quantita- tively, using benthic invertebrates in soft sediment (Commito et al. 1995a,b, Armonies 1996, Hewitt et al. 1996, Turner et al. 1997, Norkko et al. 2001, Commito \& Tita 2002, Etherington \& Eggleston 2003, Reyns \& Eggleston 2004, Commito et al. 2005). Norkko et al. (2001) directly showed that juvenile bivalves disperse over scales of meters within 1 tidal cycle. Post-larval dispersal over a relatively long distance has been suggested, based on changing temporal patterns in the horizontal distribution of juveniles (Armonies 1996, Hewitt et al. 1996, Etherington \& Eggleston 2003). Some amphipods, a major group having direct development, have wide distributions beyond more than 2 tectonic plates (Myers 1993). This evidence suggests 
that their dispersal plays an important role in the maintenance of local and regional populations (Palmer et al. 1996).

However, it remains unclear how dispersal patterns and processes of post-larval benthic organisms and species with direct development change with dispersal distance (Norkko et al. 2001). Hence, effective dispersal distance for the maintenance of local populations has been poorly described for post-larval benthic organisms and species with direct development (Palmer et al. 1996). While some studies have examined distance effects on the dispersal patterns by using plant-associated amphipods, these studies showed inconsistent patterns. For example, while dispersal was found to be limited to short distances (Gunnill 1982), dispersal rates were conversely found to increase with increases in dispersal distance (Virnstein \& Curran 1986, Tanaka \& Leite 2004). These patterns seem to be affected not only by distance effects but also by other processes.

Composition of life history stages and sizes of individuals may vary with the increase in dispersal distance in species with direct development, but to date no study has clarified the effect of dispersal distance on the size and sex composition of the colonizing individuals. Furthermore, processes of long-distance dispersal in post-larval benthic organisms and species with direct development also remain poorly understood. A possible mechanism is passive dispersal: rafting accompanying drifting substrates such as seaweeds and logs (Kingsford \& Choat 1985, Johannesson 1988, Myers 1993). If a habitat substrate drifts with the current (Kingsford \& Choat 1985), or direct developers colonize drifting substrate (Brooks \& Bell 2001), they could raft over long distances, since they do not have to depend on the time limit of the larval duration. Similarly, passive transports in the water column such as pelagic larvae (Palmer et al. 1996), which have a bedload resuspended by strong wind (e.g. Commito et al. 1995b, Turner et al. 1997, Reyns \& Eggleston 2004) and surface tension of water (Highsmith 1985), have been suggested in the literature. However, there is little empirical evidence to show that rafting and the other passive transport mechanisms are related to longdistance dispersal of species with direct development (but see Brooks \& Bell 2001).

A practical method to investigate distance effects on dispersal in marine systems is the use of recolonization experiments (e.g. Gunnill 1982, Virnstein \& Curran 1986, Tanaka \& Leite 2004). Dispersal distance is defined as the distance from the margin of the nearest natural habitat to that of the experimental patches. Thus, suitable species for the method are habitatspecialists having homogeneous habitats with a welldefined boundary that can therefore be easily mapped in the field. The amphipod Incisocalliope symbioticus (= Pleusymtes symbiotica Gamo \& Shinpo, 1992) is a suitable study organism for this aim, for the following reasons. Firstly, the amphipod is associated exclusively with the gorgonian octocoral Melithaea flabellifera (Kükenthal). The amphipod dominates the epifaunal community on the gorgonian in terms of number (usually $>80 \%$ ). Few possible competitors and predators occur on the gorgonian (Kumagai \& Aoki 2003), which often can affect dispersal patterns. Secondly, M. flabellifera populations can be mapped easily. This is because they occur only on the undersurfaces of large overhanging rock walls. Another advantage is that gorgonians including $M$. flabellifera show minimal seasonal change in the standing crop (e.g. Yoshioka \& Yoshioka 1991, Kumagai et al. 2004), unlike seaweeds and seagrasses. Thirdly, the gorgonian is suitable for experimental manipulations needed for recolonization experiments such as transplantation and complete defaunation of epifauna without destruction of samples (Kumagai et al. 2004).

In this study, short-term recolonization experiments using defaunated gorgonians over 3 distance levels $(<0.2,8,70 \mathrm{~m})$ and observations of amphipod movements in the field were carried out as a model of dispersal dynamics of marine benthic invertebrates with direct development. For this aim, the following questions were addressed: (1) How do patterns and processes of amphipod dispersal change with increases in dispersal distance? (2) What are the roles of active and passive movement in amphipod dispersal?

\section{MATERIALS AND METHODS}

Study organisms and study sites. Incisocalliope symbioticus was initially mistakenly described as Pleusymtes symbiotica by Gamo \& Shinpo (1992) but should have been placed in the genus Parapleustes (S. Ishimaru pers. comm.). After that, Bousfield \& Hendrycks $(1994,1995)$ divided Parapleustes into 7 genera, but $P$. symbiotica was not included in their studies. According to their criterion, the species should be placed in the genus Incisocalliope (S. Ishimaru pers. comm.). Thus, the name I. symbioticus was adopted in this study.

The study sites were subtidal rocky outcrops surrounded by sandy substrate in Oura Bay, Shimoda, Izu

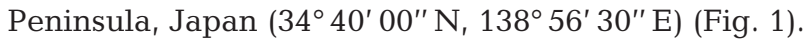
The vertical distribution of Melithaea flabellifera ranges from the upper limit of the infralittoral zone to $15 \mathrm{~m}$ in depth in Oura Bay. Other than M. flabellifera, there are only a few gorgonian colonies of Euplexaura sp. in the bay, but no Incisocalliope symbioticus has been found to occur on Euplexaura sp. (unpubl. data). 


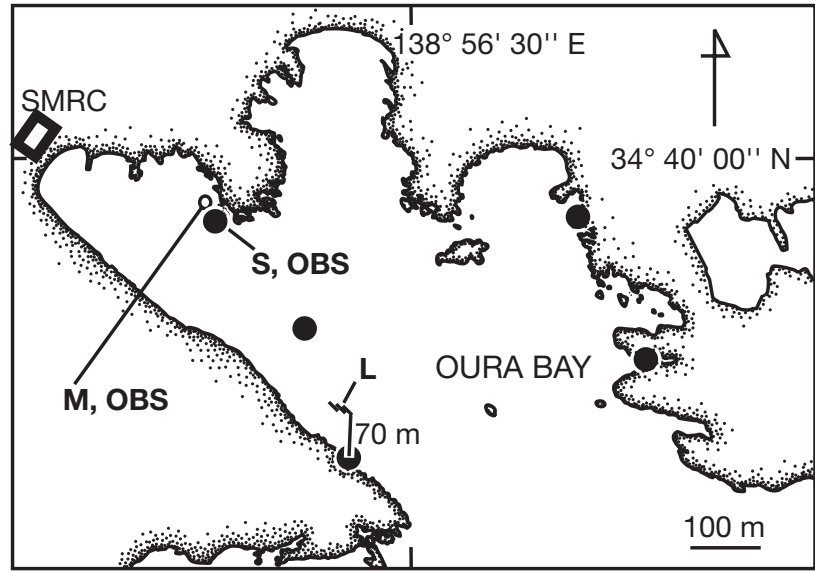

Fig. 1. Study sites in Oura Bay, Izu Peninsula, Shizuoka, Japan. = Melithaea flabellifera patch. S, M and L = sites of recolonization experiments using defaunated $M$. flabellifera colonies for short-, middle- and long-distance dispersal, respectively. $\mathrm{S}=$ largest $M$. flabellifera patch in bay, comprising 1800 colonies. Each defaunated colony was haphazardly placed within the patch; distance between a defaunated colony and adjacent intact colonies was $<0.2 \mathrm{~m}$. M = small overhanging rock wall (about $4 \mathrm{~m}^{2}$ ), $8 \mathrm{~m}$ from margin of the patch. Colonies of $M$. flabellifera were haphazardly transplanted to the undersurface of the wall. $\mathrm{L}=3$ hollow artificial concrete reefs (inner size: $0.45 \times 0.45 \times 0.60 \mathrm{~m}$ ), $0.80 \mathrm{~m}$ apart from one another. Reefs were $70 \mathrm{~m}$ from the nearest patch; 3 defaunated colonies per reef were deployed on the undersurface of the ceiling of the reefs. Obs = sites where direct observations of $I$. symbioticus movement were conducted. SMRC = Shimoda Marine Research Center

Mean height of $M$. flabellifera colonies in the bay is ca. $5 \mathrm{~cm}$ (unpubl. data). Colonies of $M$. flabellifera occur only on the undersurfaces of overhanging large rock walls. There are 5 large dense $M$. flabellifera patches in Oura Bay (Fig. 1). Each patch comprises 390 to 1800 colonies (8 to $60 \mathrm{~m}^{2}$, ca. 180 colonies $\mathrm{m}^{-2}$ ), which account for about $90 \%$ of the gorgonians in Oura Bay (unpubl. data).

Short-term recolonization experiments over 3 dispersal distances. Dispersal rate of the amphipod was investigated over 3 distance levels by recolonization experiments. All of the experimental sites were natural habitats that are now (or, prior to the experiment, were) inhabited by both Melithaea flabellifera and Incisocalliope symbioticus. Each experimental site was designed to keep the gorgonian samples in good condition even at the expense of uniformity in the construction and location of the sites. In a preliminary experiment, some gorgonian colonies that were transplanted to sites where gorgonians normally do not occur showed deterioration of condition, with the mucus covering the colony surface peeling off. Consequently, habitat generalists that are usually absent from $M$. flabellifera colonized these gorgonians instead of I. symbioticus. So long as gorgonians remain in good condition, abundance and host preference of the amphipod are affected very little by surrounding environmental conditions (unpubl. data). That is, with increasing distance of the recolonization experiments, which were carried out over scales from centimeters to $10 \mathrm{~s}$ of meters, the effects of distance will override any location effects.

Experimental sites: The short-distance dispersal was examined within the largest gorgonian patch in Oura Bay (Fig. 1). Distance among gorgonian colonies within the patch was less than $0.2 \mathrm{~m}$. The middledistance experiment was done at a small overhanging rock wall (about $4 \mathrm{~m}^{2}$ ), $8 \mathrm{~m}$ from the margin of the largest patch (Fig. 1). The rock wall was found to be inhabited by about 20 colonies of Melithaea flabellifera with Incisocalliope symbioticus during a preliminary survey in July 2001. Both gorgonians and associated amphipods were removed before the experiments. The long-distance experiment was done at the undersurface of the ceiling of 3 hollow artificial concrete reefs (inner size: $0.45 \times 0.45 \times 0.60 \mathrm{~m}$ ), which were $0.80 \mathrm{~m}$ apart from each other. The reefs were $70 \mathrm{~m}$ from the nearest natural patch of gorgonians located near the mouth of Oura Bay (Fig. 1). The reefs were set up in October 1995. During a preliminary investigation on 19 April 2000, one of the reefs was found to be colonized by a large colony of $M$. flabellifera $(18 \mathrm{~cm}$ in height, with 75 individuals of $I$. symbioticus present). This indicated that the reefs were a suitable habitat for $M$. flabellifera and I. symbioticus, even though the reefs were artificial. The gorgonian and associated epifauna were removed on 19 April 2000. Direction from large gorgonian patch to each experimental site is largely consistent with the wave direction in Oura Bay (see Obara 1937). The shortest distance of the short-, middle- and long-dispersal experiments was, respectively, <0.2 $\mathrm{m}$ (within a local population), $8 \mathrm{~m}$, and $70 \mathrm{~m}$ (distances representing among local populations). No gorgonian was found in any direction within the studied distances of the middle- and long-distance dispersals.

Preparation of experiments: Gorgonian samples, 5 to $12 \mathrm{~cm}$ in height, were haphazardly collected in Oura Bay 1 to $4 \mathrm{~d}$ before each experiment. At each experimental time, new samples were deployed. The whole colony was collected by detaching its base from the substratum in the middle- and long-distance experiments. In contrast, the basal 1 to $2 \mathrm{~cm}$ part of the stem was left for the short-distance experiment. Until initiation of the experiments, collected samples were kept hanging in the running seawater pool at Shimoda Marine Research Center, University of Tsukuba (Fig. 1). The samples were completely defaunated: the majority of amphipods were removed by repeated sub- 
mersion and emersion of gorgonian samples in seawater, and residual animals were removed by pipetting under a binocular microscope. The defaunation was finished within 5 to 20 min and with minimal change of water temperature. This was a successful method of defaunation, because treated gorgonian samples showed no apparent damage. Additionally, Incisocalliope symbioticus individuals on each gorgonian sample collected for the short-distance experiments on 7 May, 27 June and 30 August 2002 were examined and the data used for the control as a 'resident population'.

Experimental procedure: Dispersal rate of the amphipod over 1 wk was measured at each transplanted or reattached gorgonian sample. The experimental period was set at $1 \mathrm{wk}$ to avoid possible increase of individuals by the reproduction of colonizers, which should not occur within this time period. Increase by reproduction during the experimental period(s) of this study was negligible. If it had not been negligible, composition of amphipod samples would have been strongly biased, i.e. 1 mature female and many small juveniles within 1 gorgonian sample, but no such compositions were observed throughout the study. The short-distance experiments were conducted from May 2001 to September 2002 with 1 to 3 mo intervals. The gorgonian samples used for the experiments were reattached to their original stems with a rubber band (diameter: $18 \mathrm{~mm}$ ); see details in Kumagai et al. (2004). This method was different from that of the middle- and long-distance experiments, to avoid breaking or affecting adjacent natural gorgonian colonies. However, the reattachment procedure broke some of original stems, and thus the number of the gorgonian samples varied between 3 and 8 . The middle- and long-distance dispersals were investigated between August 2001 and December 2002 on a fortnightly or monthly basis. For the middle- and long-distance experiments, 6 and 9 samples, respectively, were used at a time. Samples for the middle-distance experiment were haphazardly transplanted to the undersurface of the small overhanging rock wall. For the long-distance experiment, 3 samples per artificial concrete block were transplanted. The distance among samples within a block was about $15 \mathrm{~cm}$. For the middle- and long-distance experiments, each gorgonian sample was attached to a projection (ca. $2 \mathrm{~cm}$ ) with a plastic base, using a short piece of polypropylene tubing. The projections were affixed to the substrate at each study site beforehand; see details of the transplantation techniques in Kumagai et al. (2004).

Treatment of samples: At retrieval, each gorgonian sample was gently enclosed by a plastic bag down to the stem and detached, preventing amphipods from escaping. The retrieved samples were immediately brought back to the laboratory and examined under a binocular microscope. For each sample, all amphipods were carefully separated and counted. After removal of all epifauna, the wet weight of each gorgonian sample was measured. The dispersal rates of amphipods were calculated per unit wet weight of each gorgonian sample. Furthermore, amphipod samples were categorized into newly hatched, juveniles, males, immature females and mature females. Individuals with a pair of penial papillae on the ventral side were defined as males, those having oostegites with marginal setae as mature females, those without the setae as immature females, and those not having any of these characters as juveniles. Among juveniles, individuals having a 5 -segmented flagellum on the first antenna and belonging to the smallest size class were identified as 'newly hatched', because the first antenna of all hatched juveniles in the brood pouch also have a 5 -segmented flagellum on the first antenna (unpubl. data). There is no readily useable criterion for assessing sexual maturity in males. After sex and stage discrimination, cephalon length was measured for all specimens obtained in the middle- and long-distance experiments. Subsamples were examined for the resident population and short-distance dispersal experiment: amphipod specimens from 4 gorgonian samples were randomly selected from each and examined. Cephalon length of the amphipod specimens was measured using a video micrometer (YM-60, Olympus) connected to a binocular microscope.

The data were pooled over the whole study period (May 2001 to December 2002) to increase the number of samples, and the composition of stages and sexes and size-frequency distributions were then compared among the resident population and colonizers in each of the dispersal experiments. To confirm the validity of the pooled data, data limited only to the summer of 2002 were also analyzed; the pattern of changes in composition was consistent with that of the former, and thus only pooled data are shown.

Observations of amphipod movements in the field. Observations of amphipod movement were conducted around the largest gorgonian patch mentioned above (Fig. 1). In order to examine the ability to settle on the gorgonian, movements of the amphipod from 2 release points were directly observed. Gorgonian colonies and undersurface of the rock walls were hidden from both of the points by the overhang. Point A was $2 \mathrm{~m}$ from the margin of the gorgonian patch. Point B was $8 \mathrm{~m}$ from the margin of the patch and $2 \mathrm{~m}$ from the small overhanging rock wall (Fig. 2). The rock wall was defaunated before the experiments as described above. Release depth at both points was $0.5 \mathrm{~m}$. Water depth at Point A was $3 \mathrm{~m}$ and that of Point B was $2 \mathrm{~m}$.

In order to distinguish active transport from passive transport, movements of living and dead amphipod 


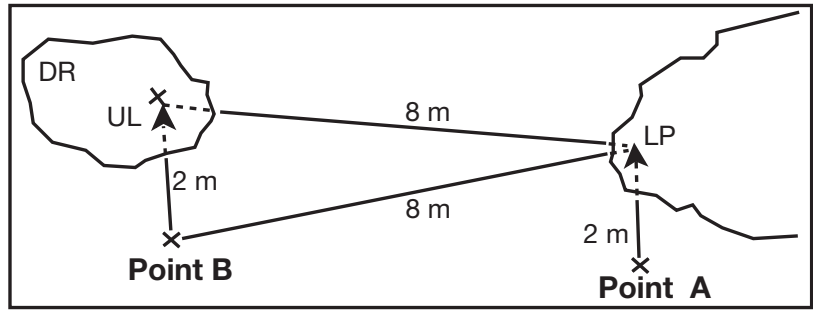

Fig. 2. Incisocalliope symbioticus. Top view of release points (A \& B) in observation experiments in relation to position of the Melithaea flabellifera patch and small overhanging rock wall. LP = largest $M$. flabellifera patch in Oura Bay. DR = defaunated small overhanging rock wall, originally inhabited by $M$. flabellifera and I. symbioticus. They were removed before the experiments. UL = upper limit originally inhabited by $M$. flabellifera. Colonies of $M$. flabellifera and undersurface of rock walls were hidden from both points by the overhang

specimens were compared. Living specimens were comprised of 20 intact amphipods, whose body length was 1.5 to $4.0 \mathrm{~mm}$ (juveniles to adults). The same number and approximate size range of dead amphipods was used as a control. Live specimens were collected at the largest patch (Fig. 1) 1 day in advance of observations. Dead specimens were collected at the patch $1 \mathrm{wk}$ before observations, and were fixed in neutralized $5 \%$ formalin in seawater and dyed with Rose Bengal. The observations were conducted on the morning of 25 May 2004 (neap tide). Surf condition was very calm and water temperature was $20.1^{\circ} \mathrm{C}$. At each release point, the specimens were released one by one, and each specimen was observed by a diver for $3 \mathrm{~min}$. Arrival or non-arrival was confirmed for each specimen. The time required for each amphipod to move from the release points to the margin of the gorgonian patch was measured with a stopwatch. If the specimen arrived at the patch, the time was recorded.

Data analyses. Overall differences in amphipod density and dispersal rates were tested using 2-way ANOVA, with experiments (the resident populations and colonizers over 3 distance levels) and months as factors. If significant differences were found, multiple pairwise comparisons were done and the $\mathrm{p}$-values adjusted to an overall level using the sequential Bonferroni correction (Sokal \& Rohlf 1995). In the same way, changes in the composition of life history stages and sexes (reflected by changes in shape of size-frequency distribution) were tested using chi-square tests with the sequential-Bonferroni correction. Overall changes in location of sizefrequency distribution were examined by KruskalWallis test, and multiple comparisons were done by Mann-Whitney $U$-test. The p-values for these analyses were adjusted with the sequential-Bonferroni correction. The differences in size frequency distributions represented differences in the composition of life history stages, which were already analyzed using chi-square tests. Temporal changes in the dispersal rate were analyzed by 1-way ANOVA. Furthermore, multiple forward stepwise regression analyses were performed to determine which combination of dependent variables best accounted for the variation in each dispersal rate over short-, middle- and long-distance dispersal.

Dependent variables used for the analyses were (1) the density of the resident population of the amphipod (Kumagai \& Aoki 2003), (2) the water temperature of the population (unpubl. data), (3) daily marine meteorological data at Cape Irozaki $\left(34^{\circ} 36^{\prime} \mathrm{N}, 138^{\circ} 51^{\prime} \mathrm{E}\right.$ : near to the study site), (4) monthly wave data of the maximum significant wave height at Shimoda Bay $\left(34^{\circ} 40^{\prime} \mathrm{N}, 138^{\circ} 57^{\prime} \mathrm{E}\right.$ : adjacent to the study site) (data available from www.pari.go.jp), as indices of the hydrodynamic drag force, and (5) the persistence rate of transplanted gorgonian samples (Kumagai et al. 2004). The persistence rate was obtained from the ratio of the number of the remaining transplanted gorgonians to their initial number. The persistence rate was also used as an index of the hydrodynamic force, because loss of gorgonian samples was due to detachment by hydrodynamic force of wave, which is the major cause of death in gorgonians (Yoshioka \& Yoshioka 1991, Kumagai et al. 2004). All the remaining gorgonians were in good condition. The mean persistence rates of the short-, middle- and long-distance experiments were, respectively, 89.6, 84.6 and 97.7\% (Kumagai et al. 2004).

The meteorological data taken at Cape Irozaki included mean wind speed, maximum instantaneous wind speed, mean sea level pressure, and minimum of mean sea level pressure (data from www.data.kishou. go.jp, and shown in Kumagai et al. 2004). Wave height data were not obtained for the 5 experimental times, and the df decreased to 18 for the middle and long dispersals. The relative importance of each variable in affecting each of the dispersal rates was assessed by evaluation of the adjusted $\mathrm{R}^{2}$ value after its addition to a regression model. Multiple forward stepwise regression works by sequentially adding variables to the regression equation only if there is significant improvement to the coefficient of determination. In the direct observation of amphipod movement, arrival probability at the gorgonian patch was tested by the binomial test.

\section{RESULTS}

\section{Distance effects on dispersal rate}

Dispersals were observed over all distances (Fig. 3). The dispersal rates over the 3 distance levels and the density of the resident population were compared 


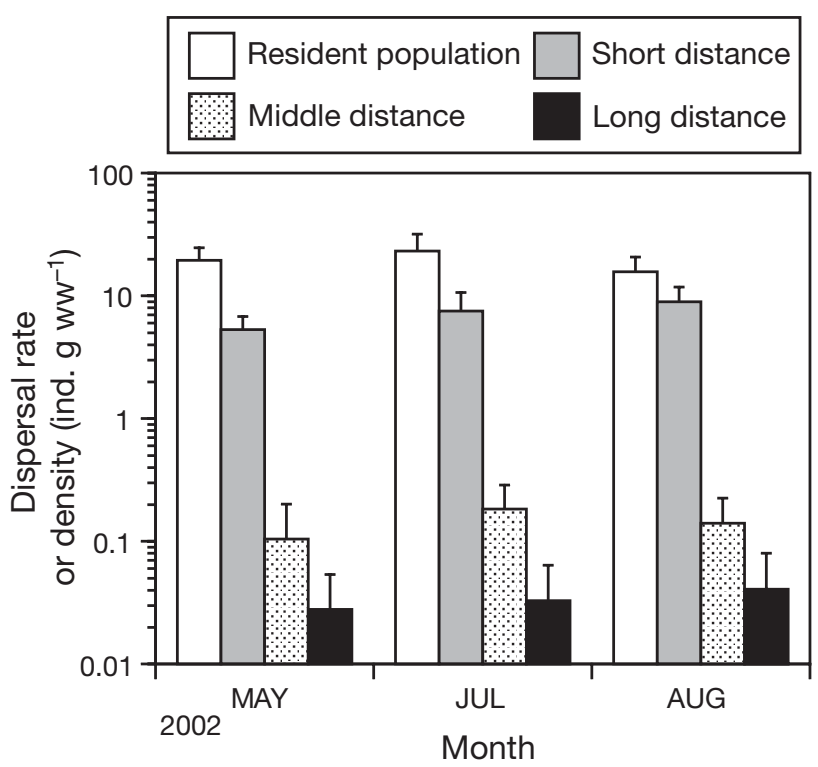

Fig. 3. Incisocalliope symbioticus. Dispersal rates onto defaunated Melithaea flabellifera colonies over $1 \mathrm{wk}$ for different experimental distance levels, and density of resident population (no. of ind. per unit wet weight [WW] M. flabellifera). Data (mean $+\mathrm{SE})$ shown on a log scale. Resident population $=$ density of natural population. $\mathrm{N}=5$ for resident population and short distance; $=6$ for middle distance $=9$ for long distance

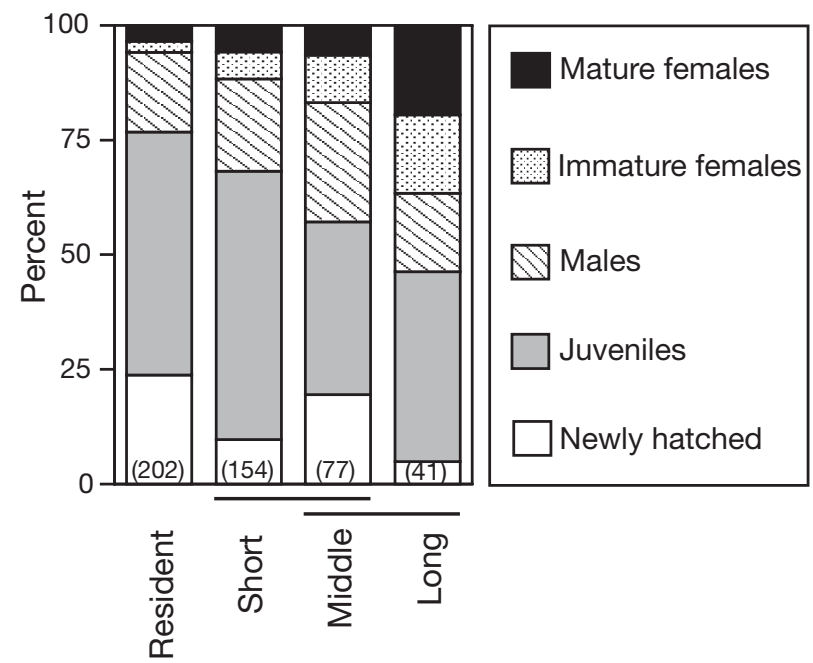

Fig. 4. Incisocalliope symbioticus. Life history stages and sexes of resident population and colonizers onto defaunated Melithaea flabellifera colonies over $1 \mathrm{wk}$ for different experimental distance levels (short, middle and long). Data are pooled over whole study period (May 2001 to December 2002). Data of all I. symbioticus are shown for middle- and long-distance dispersals, whereas subsamples are used for the resident population and short-distance dispersal (see 'Materials and methods'). Numbers in parentheses indicate no. of ind. examined. Horizontal bars join groups that do not differ significantly ( $p>0.05)$, based on multiple pairwise comparisons with sequential-Bonferroni correction (Sokal \& Rohlf 1995)

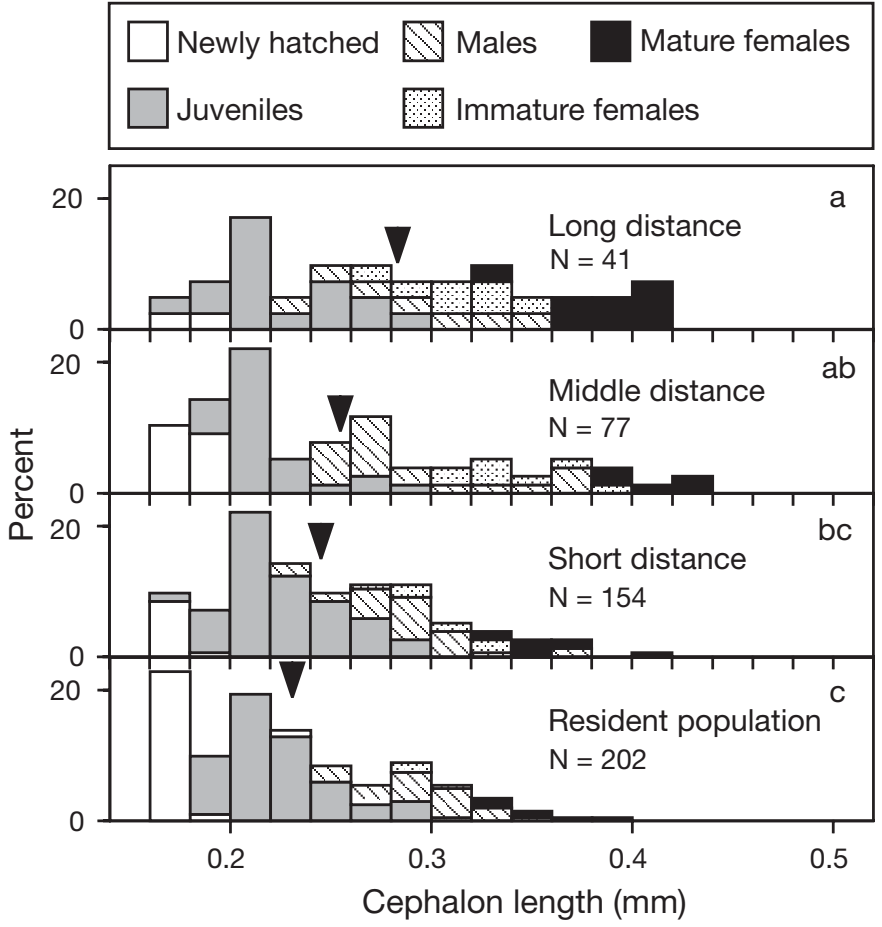

Fig. 5. Incisocalliope symbioticus. Size frequency distribution of resident population and colonizers onto defaunated Melithaea flabellifera colonies over 1 wk for different distance levels. Data pooled over whole study period (May 2001 to December 2002). Data from all I. symbioticus shown for middle- and long-distance dispersals, whereas subsamples shown for resident population and shortdistance dispersal (see 'Materials and methods'). $\mathrm{N}=$ no. of ind. examined. Arrowheads indicate mean. Histograms sharing same letter $(a, b, c)$ do not differ significantly $(p>0.05)$ in multiple pairwise comparisons using Mann-Whitney $U$-tests with sequentialBonferroni correction (Sokal \& Rohlf 1995)

among May, June-July and August 2002. Dispersal rates drastically decreased with increase in distanceby about 1 order of magnitude with an increase of 1 distance level-and dispersal rates over the shortdistance were from 30 to $80 \%$ of the density in the resident population (2-way ANOVA: $\mathrm{df}=3, \mathrm{MS}=1365$, $F=24.43, p<0.0001 ;$ significant differences were found among the dispersal rates except between those of the middle- and long-distance dispersals by multiple pairwise comparisons using the sequential-Bonferroni correction).

Although all life history stages and sexes of individuals dispersed over all distances, composition of stages and sexes changed with increasing dispersal distance $\left(\chi^{2}=50.74, p<0.0001\right)$ (Fig. 4). Proportions of females increased with dispersal distance. Mature females of the resident population and colonizers over the short, middle and long distance were 3.5, 5.8, 6.5 and 19.5\%, respectively. Size structure also changed with dispersal distance (Kruskal-Wallis test: $H=26.45, \mathrm{p}<0.0001$ ) 
(Fig. 5). Proportions of larger individuals increased with distance. Mean cephalon lengths in the resident population and in colonizers over the short, middle and long distance were $0.23,0.25,0.26$ and $0.28 \mathrm{~mm}$, respectively.

\section{Temporal changes in the dispersal rate}

Temporal changes in the dispersal rate are shown for the 3 distance levels (Fig. 6). Dispersal rates over each of the distances were observed throughout the year, and changed temporally (short distance: ANOVA, df =

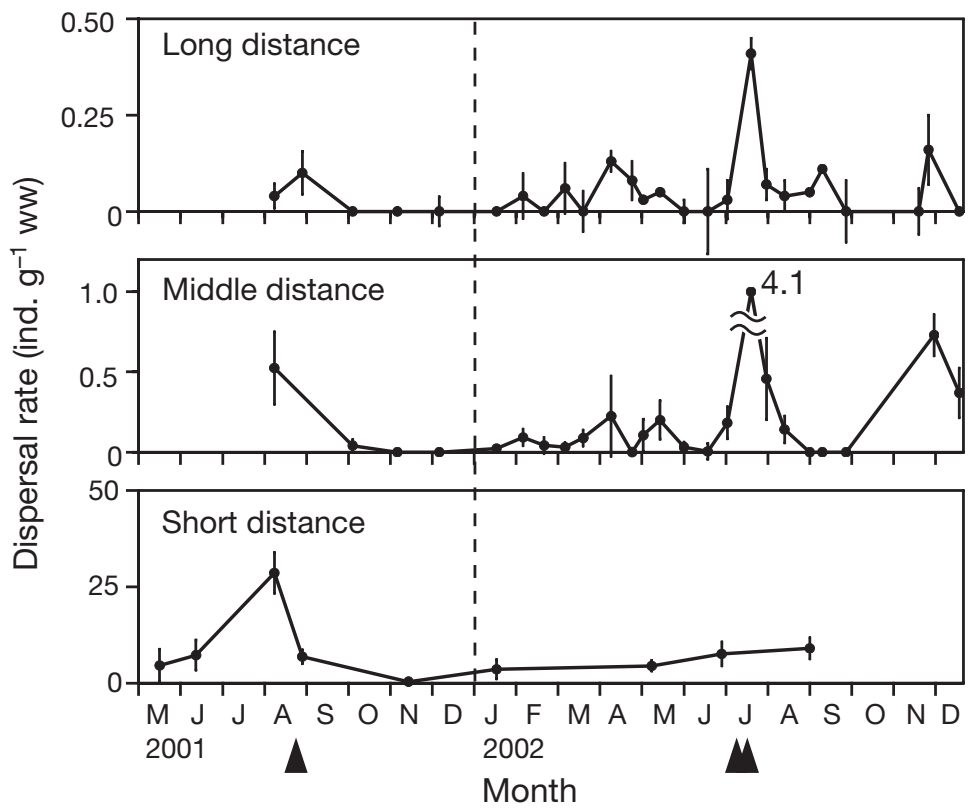

Fig. 6. Incisocalliope symbioticus. Temporal changes in dispersal rate (no. of ind. per unit wet weight [WW] Melithaea flabellifera) onto defaunated M. flabellifera colonies from May 2001 to December 2002 (mean $\pm \mathrm{SE})$. Each point represents end of each 1 wk experimental period. No. of replicates $=3$ to 8 for short distance; 6 for middle distance; 9 for long distance. At each experimental time, new colonies were deployed. Arrowheads indicate times when the center of a typhoon passed within $10 \mathrm{~km}$ of the study site
8, $\mathrm{MS}=270.9, F=5.85, \mathrm{p}<0.001 ;$ middle distance: $\mathrm{df}=$ 23, $\mathrm{MS}=0.847, F=12.4, \mathrm{p}<0.0001$; long distance: $\mathrm{df}=$ 25, $\mathrm{MS}=0.058, F=3.22, \mathrm{p}<0.0001)$. Apparent increases in dispersal rates over the middle and long distance occurred mainly in the spring and summer. Additionally, a peak in dispersal rate was also observed in the latter part of November 2002. Multiple forward stepwise regressions accounted for fairly high percentages of the variation in dispersal rates (Table 1). Regression analysis revealed that $84.8 \%$ of the variance in the dispersal rate over the short distance is explained by inclusion of the population density and water temperature at the study site. In contrast, $87.4 \%$ of the middle-distance dispersal is predicted by the persistence rate of gorgonian samples and the maximum instantaneous wind speed. Similarly, $67.0 \%$ of the long distance dispersal is accounted for by the persistence rate of samples. Furthermore, remarkable increases in the dispersal rate over the middle and long distances were coincident with periods of direct effects of typhoons striking this area (the center of a typhoon passed within $10 \mathrm{~km}$ of the study site) (Fig. 6).

\section{Observations of amphipod movement}

When the 20 live amphipod specimens were released at Point A (Fig. 2), 17 specimens swam straight to the gorgonian patch and reached the patch within $1 \mathrm{~min}$, but 3 individuals showed no clear directional movement and drifted away in the water column (binomial test: $\mathrm{p}<0.01)$. Movement speed of the arrivals was $3.41 \pm 1.05 \mathrm{~m} \mathrm{~min}^{-1}$ (mean $\pm \mathrm{SD}$ ). All dead specimens released in the same manner at Point A drifted away ( $\mathrm{p}<0.0001)$. When live specimens were released at Point B, they swam in all directions, but none moved toward the small rock ( $p<0.0001)$. Furthermore, among the specimens, 6 specimens

Table 1. Incisocalliope symbioticus. Summary of multiple forward stepwise regression analyses for temporal variations in the dispersal rate onto defaunated Melithaea flabellifera colonies. Dependent variables used in analyses were (1) density of $I$. symbioticus resident population, (2) water temperature, (3) persistence rate of $M$. flabellifera samples, (4) meteorological data at Cape

Irozaki, (5) wave data at Shimoda Bay; see 'Materials and methods' for data sources. $\beta=$ standard regression coefficients

\begin{tabular}{|c|c|c|c|c|c|}
\hline & $\mathrm{df}$ & $\mathrm{R}^{2}$ & $\mathrm{p}$ & Dependent variables & $\beta$ \\
\hline Short distance & 8 & 0.848 & $<0.01$ & $\begin{array}{l}\text { Population density of } I \text {. symbioticus } \\
\text { Water temperature }\end{array}$ & $\begin{array}{l}0.670 \\
0.649\end{array}$ \\
\hline Middle distance & 18 & 0.874 & $<0.0001$ & $\begin{array}{l}\text { Persistence rate of samples } \\
\text { Maximum instantaneous wind speed }\end{array}$ & $\begin{array}{r}-0.825 \\
0.318\end{array}$ \\
\hline Long distance & 18 & 0.670 & $<0.0001$ & Persistence rate of samples & -0.853 \\
\hline
\end{tabular}


were trapped in the surface tension of water, and 1 of them returned to the water column. All dead specimens released in the same manner at Point B drifted away $(p<0.0001)$. These results suggested that (1) active transport is necessary to reach the gorgonian even in the shortdistance dispersal, (2) the cue of the amphipod movement is not the topography of gorgonian habitat (overhanging rock) but the presence of the gorgonian, and (3) the cue is not visual, because the amphipod swam toward the gorgonian colonies hidden by an overhang. Thus, the cue might be a diffusive chemical cue originating from the gorgonian.

\section{DISCUSSION}

\section{Distance effects on dispersal patterns}

The present study showed that the rate (Fig. 3) and composition (Figs. 4 \& 5) of dispersing Incisocalliope symbioticus changed with increasing dispersal distance. Dispersal rate of $I$. symbioticus decreased with increasing dispersal distance (Fig. 3). Though distance effects on the dispersal rate of amphipods were investigated by recolonization experiments using patches of single macroalgal species (Gunnill 1982, Tanaka \& Leite 2004) and artificial seagrass (Virnstein \& Curran 1986), results of those studies were not consistent with those of the present study. Dispersals were observed only over short distances (<5 m) by Gunnill (1982) and dispersal rates increased with increasing distance in Virnstein \& Curran (1986) and Tanaka \& Leite (2004).

There are 2 possible reasons for these differences. The first is related to habitat preference; most amphipod species associated with macroalgae and seagrasses show a low degree of species-specificity among host-plant species (reviewed in Hay \& Fenical 1988). If other algal species appear around the experimental patch of the studied host species, rates of recolonization and emigration by the studied amphipod species can be affected by their existence. In other words, if the amphipod prefers the experimental patch to other neighboring algal species, amphipods can migrate from the neighboring algae to the experimental patch and amphipod abundance in the patch can exceed that of the resident population, and vice versa (see Poore 2004). In contrast, Incisocalliope symbioticus occurs only on Melithaea flabellifera, and no other possible host occurred between or around the natural patches and the experimental patches.

The second reason is a difference in predation risk. Virnstein \& Curran (1986) suggested that increasing dispersal rate with increasing dispersal distance is due to escape from predation: emigrants from natural populations aggregate in the nearest refuge from preda- tion risk. Amphipods on seaweeds and seagrasses are often subjected to heavy predation (Van Dolah 1978, Nelson 1979a,b, Stoner 1980), whereas Incisocalliope symbioticus rarely experiences predation when associated with Melithaea flabellifera (unpubl. data). Therefore, the decrease in dispersal rate in I. symbioticus would simply represent only distance effects from the source population.

In dispersing Incisocalliope symbioticus, the proportions of mature females and of larger individuals increased with increasing dispersal distance (Figs. 4 \& 5). Though no previous study has shown changes in the composition of dispersing marine invertebrates with increasing dispersal distance, there are some examples that demonstrate that composition is different between resident populations and populations after emigration. Similar to the present study, Poore \& Steinberg (1999) showed in a laboratory experiment that more adult than juvenile amphipods migrate among host algal species. In the tidal-flat amphipod Corophium volutator, larger proportions of adult males or small juveniles were observed during emigration, in the water column and at settlement, than in the resident population (Hughes 1988, Lawrie \& Raffaelli 1998). Dispersal of those juveniles may be densitydependent, and those adult males may disperse searching for a mating partner (Hughes 1988, Lawrie \& Raffaelli 1998). The dispersal of post-larval small juvenile blue crabs is density-dependent (Reyns \& Eggleston 2004). Similarly, larger proportions of small individuals of bivalves dwelling in soft sediment actively disperse (Norkko et al. 2001). In contrast, dispersal of an ovoviviparous bivalve is passive, and size structure does not change between re-colonizing populations and resident populations (Commito et al. 1995a).

With regard to the effects of dispersal on the maintenance of local populations, dispersal patterns of Incisocalliope symbioticus indicate that there are opposite processes between marine benthic organisms with direct development and those with pelagic larval stages. Dispersal of benthic organisms with pelagic larval stages is generally restricted to the larval or small juvenile stages. Despite their high potential for dispersal, effects of colonization on the maintenance of local populations are unclear because usually only a few of colonizers survive due to the high mortality that exists between colonization and the reproductive stage (Underwood \& Fairweather 1989). On the other hand, in spite of the low frequency of dispersal (Fig. 3), I. symbioticus shows a tendency for larger proportions of females and large individuals to disperse farther while small juveniles stay in a local population (Figs. 4 \& 5). This tendency is advantageous for reproduction after colonization, because those females and large individuals can start reproduction within a short time after 
colonization, and thus can establish breeding aggregations at the colonized site as predicted by Johannesson (1988). Thus variation in the colonization rate of females can directly affect population persistence of species with direct development. In contrast, that of males will hardly affect population persistence because 1 male is sufficient for fertilization. Furthermore, if emigrating females are already fertilized, there is no need for males to disperse. Therefore, females should disperse farther even if mortality during dispersal is high, regardless of the stability of the gorgonian patches (Kumagai et al. 2004) as predicted by Hamilton \& May (1977).

Additionally, colonizers can start reproduction throughout the year, because reproduction (unpubl. data) and dispersal (Fig. 6) of Incisocalliope symbioticus occurs all year round. Consequently, dispersal rates of $I$. symbioticus over the long distance (representing distances among local populations) were quite small (Fig. 3) and thus colonizers themselves may not markedly affect density of the overall population in Oura Bay, unlike benthic invertebrates undertaking post-larval dispersal (Reyns \& Eggleston 2004). However, those colonizers have the potential for rapid establishment of a breeding aggregation (Figs. 4 \& 5), and may therefore be responsible for the maintenance of local populations. This trait is more similar to that of insects rather than that of other marine benthic invertebrates and fishes. This is because dispersal is largely due to adults with higher dispersal ability, which can immediately start reproduction after colonization, as is also observed for insects (Begon et al. 1996).

\section{Dispersal process}

Major processes driving Incisocalliope symbioticus dispersal seem to be different between shorter- and longer-distance dispersals. In the middle- and the long-distance dispersals, dispersal rates changed with an index of the hydrodynamic drag force (Table 1). This means that the amphipod was passively transported over the long distance. A possible long-distance dispersal mechanism for amphipods is rafting (Kingsford \& Choat 1985, Johannesson 1988). However, there is little probability that Melithaea flabellifera colonies drift over large distances. Colonies of the gorgonian seem to detach and sink down to the bottom, because its specific gravity is greater than that of seawaterdetached colonies are often found on the sea bottom just below the patch after typhoon events (pers. obs.). Furthermore, I. symbioticus would not colonize drifting substrates such as seaweeds because the amphipod has a strong habitat specificity to the gorgonian (unpubl. data). Thus, the mechanism of long-distance dispersal of $I$. symbioticus is not considered to be rafting.

Other possible passive dispersal mechanisms for amphipods have also been suggested: drift by winddriven currents in the water column (e.g. Commito et al. 1995b, Turner et al. 1997, Reyns \& Eggleston 2004), and in the surface tension of seawater (Highsmith 1985). There are currents along the coast in Oura Bay (Obara 1937). The currents can assist Incisocalliope symbioticus in reaching Melithaea flabellifera patches, located along the coast in Oura Bay. Indeed, some live specimens of $I$. symbioticus were trapped in the surface tension of seawater, as proposed by Highsmith (1985). Furthermore, remarkable increases in the dispersal rate were coincident with the effects of typhoons (Fig. 6). Therefore, strong hydrodynamic drag force during typhoon and storm events may be a major cause of long distance dispersal of $I$. symbioticus.

Active transport would be the major dispersal mechanism of Incisocalliope symbioticus over a short distance, because the amphipod has sufficient swimming ability, similar to other free-living amphipods (Ingòlfsson \& Agnarsson 2003), and much greater than that of zooplankton such as copepods (e.g. Seuront et al. 2004). Similarly, amphipods inhabiting seagrass and macroalgal beds actively swim and frequently move within a bed (e.g. Howard 1985). Furthermore, rates of short-distance dispersals changed seasonally with the density of the resident population, as found for the dispersals of other amphipods (Franz \& Mohamed 1989, Tanaka \& Leite 2004) and of other marine benthic organisms with direct development (e.g. Commito et al. 1995a). These patterns may have resulted from density-dependent active transport (Franz \& Mohamed 1989, Tanaka \& Leite 2004).

Long-distance dispersal of Incisocalliope symbioticus cannot be entirely passive. If this were the case, the composition of the colonizers would not change with increasing dispersal distance after emigration (Commito et al. 1995a, Norkko et al. 2001). Actually, the proportions of females and large individuals increased with dispersal distance (Figs. 4 \& 5). Three working hypotheses are considered as the mechanism of longdistance dispersal of I. symbioticus. (1) Long dispersal of $I$. symbioticus itself is entirely passive. At emigration, wave drag force detaches larger amphipods from colonies of Melithaea flabellifera more easily than smaller ones. During dispersal, predators such as fishes selectively consume smaller individuals and males, and thus result in the observed composition of dispersing amphipods. The degree of change expands with the increasing amount of time required for dispersal. (2) Conversely, an entirely active dispersal mechanism is also possible. More females and larger individuals actively emigrate during storm and typhoon 
events. Females and larger individuals have a greater ability to swim and to find other $M$. flabellifera patches. (3) Combination of the passive and active movements causes the observed dispersal patterns.

In relation to the first hypothesis, if dispersal is entirely passive, the vast majority of emigrants would disperse only to become lost (see 'Results': Observations of amphipod movement). To realize the observed dispersal rates over the long distance (Fig. 3), enormous numbers of individuals would have to emigrate. In that case, increase in dispersal rates may cause a severe decrease in population density. However, none of the dispersal rates were negatively correlated with population density (Table 1). This indicates that the dispersal of the amphipod is not entirely passive. Furthermore, fishes generally selectively consume larger amphipods rather than small ones (Nelson 1979a, Sudo \& Azeta 1992, Edgar \& Aoki 1993), contrary to this hypothesis. This is often interpreted as optimal foraging, where smaller prey items encountered by fishes are ignored due to their low energetic content (Charnov 1976). Similarly, in terms of energetic content, the values of females (particularly individuals with embryos) are obviously larger than males. This also falsifies the first hypothesis.

Considering the second hypothesis, the time required for Incisocalliope symbioticus to swim over $70 \mathrm{~m}$ (the distance for the long-dispersal experiments) is estimated to be less than 20 min when simply calculated from the swimming speed obtained in the observations. The swimming ability might be enough not only for the short-distance dispersals but also the middle- and long-distance dispersals. However, the hydrodynamic drag force during typhoons and storms may be too strong for amphipods to move actively. If possible, it may be too wasteful in terms of energy consumption. Therefore, the most likely hypothesis is the third one above, i.e. the driving force of the long-distance dispersal is more passive than active, but the emigration and control of direction is due to active movement. Females and larger individuals have a greater ability to swim and to find Melithaea flabellifera patches. Active swimming may play a more important role (particularly in selecting the dispersal direction) than previously suggested (Palmer et al. 1996).

\section{Dispersal traits as a habitat specialist}

As a habitat specialist there are 2 difficulties faced by Incisocalliope symbioticus in the process of dispersal. One difficulty is that the occurrence of suitable habitat for colonization in the coastal area is infrequent. In order to encounter habitat patches, precise locating ability is needed for habitat specialists (reviewed in Pawlik
1992). Within at least $2 \mathrm{~m}$ in calm sea conditions, the amphipod might utilize diffusive chemical cues originating from the gorgonian for location (see 'Results: Observations of amphipod movement'). Indeed, waterborne compounds are thought to be used as a cue for settlement in some marine habitat specialists (reviewed in Pawlik 1992). Furthermore, there was a peak in dispersal rate over the middle and long distance in the latter part of November 2002 (Fig. 6), despite the low density in the resident population (Kumagai \& Aoki 2003). The evidence supports the notion that I. symbioticus is capable of efficient migration utilizing large water movements during storm and typhoon events.

Another difficulty is the predation risk faced during dispersal in the water column. Host specialization of some specialist amphipods on noxious hosts may be explained as a strategy to escape heavy predation (e.g. Hay et al. 1987, 1990, Duffy \& Hay 1994). Gorgonians are also chemically well-protected (reviewed in Coll 1992). Therefore, for habitat specialists like Incisocalliope symbioticus, dispersal in the water column is potentially the most risky period of their life. In fact, $I$. symbioticus is easily consumed by fish in the still and clear water column (pers. obs.). However, storms and typhoons can help the amphipod to disperse more safely. During storms and typhoons, extremely increased turbidity and turbulence of seawater may reduce predation by fishes (MacKenzie et al. 1994, Utne 1997). In summary, I. symbioticus may utilize diffusive chemical cues originating from the gorgonian to precisely locate and use typhoon and storm events to minimize predation risk during dispersal.

\section{CONCLUSION}

The dispersal rate of Incisocalliope symbioticus decreased with increasing dispersal distance from the source population, but the proportion of females and larger individuals increased. The dispersal rates over the long distance (representing the distance among local populations) were quite small, and thus colonizers themselves may not markedly affect the density of the overall population. However, those colonizing larger females had the potential for rapid establishment of breeding aggregations, and therefore were responsible for the maintenance of local populations. This trait is more similar to that of insects rather than that of marine benthic organisms with pelagic larval stages. The mechanism of long-distance dispersal of the amphipod seems to be largely passive transport, driven by typhoon and storm events. Nevertheless, active transport (required to move toward and to locate habitat patches) was also a necessary component of migration, because the habitat of the amphipod only occurs sporadically. 
Acknowledgements. I am very grateful to Dr. M. N. Aoki for his generous support and critical reading of this manuscript. I thank Dr. S. Ishimaru for identification of Incisocalliope symbioticus. Thanks are due to Y. Tsuchiya, T. Sato and H. Shinagawa for their assistance with the diving fieldwork. I am grateful to colleagues at the Shimoda Marine Research Center for their valuable suggestions. The comments of Dr. C. Norman and 4 anonymous reviewers greatly improved this manuscript. This is contribution number 716 from the Shimoda Marine Research Center, University of Tsukuba.

\section{LITERATURE CITED}

Armonies W (1996) Changes in distribution patterns of 0-group bivalves in the Wadden Sea: byssus-drifting releases juveniles from the constraints of hydrography. J Sea Res 35:323-334

Begon M, Harper JL, Townsend CR (1996) Ecology. Blackwell Scientific Publications, Oxford

Bousfield EL, Hendrycks EA (1994) A revision of family Pleustidae (Amphipoda: Gammaridea) Part I. Systematics and biogeography of component subfamilies. Amphipacifica 1:17-57

Bousfield EL, Hendrycks EA (1995) The amphipod family Pleustidae on the Pacific coast of North America: Part III. Subfamilies Parapleustinae, Dactylopleustinae, and Pleusirinae. Systematics and distributional ecology. Amphipacifica 2:65-133

Brooks RA, Bell SS (2001) Mobile corridors in marine landscapes: enhancement of faunal exchange at seagrass/sand ecotones. J Exp Mar Biol Ecol 264:67-84

Charnov EL (1976) Optimal foraging, the marginal value theorem. Theor Popul Biol 9:129-136

Coll JC (1992) The chemistry and chemical ecology of octocorals (Coelenterata, Anthozoa, Octocorallia). Chem Rev 92:613-631

Commito JA, Tita G (2002) Differential dispersal rates in an intertidal meiofauna assemblage. J Exp Mar Biol Ecol 268:237-256

Commito JA, Currier CA, Kane LR, Reinsel KA, Ulm IM (1995a) Dispersal dynamics of the bivalve Gemma gemma in a patchy environment. Ecol Monogr 65:1-20

Commito JA, Thrush SF, Pridmore RD, Hewitt JE, Cummings VJ (1995b) Dispersal dynamics in a wind-driven benthic system. Limnol Oceanogr 40:1513-1518

Commito JA, Celano EA, Celico HJ, Como S, Johnson CP (2005) Mussels matter: postlarval dispersal dynamics altered by a spatially complex ecosystem engineer. J Exp Mar Biol Ecol 316:133-147

Duffy JE, Hay ME (1994) Herbivore resistance to seaweed chemical defense: the roles of mobility and predation risk. Ecology 75:1304-1319

Edgar GJ, Aoki M (1993) Resource limitation and fish predation: their importance to mobile epifauna associated with Japanese Sargassum. Oecologia 95:122-133

Etherington LL, Eggleston DB (2003) Spatial dynamics of large-scale, multi-stage crab (Callinectes sapidus) dispersal: determinants and consequences for recruitment. Can J Fish Aquat Sci 60:873-887

Franz DR, Mohamed Y (1989) Short-distance dispersal in a fouling community amphipod crustacean, Jassa marmorata Holmes. J Exp Mar Biol Ecol 133:1-13

Gamo S, Shinpo Y (1992) A new gammaridean amphipod, Pleusymtes symbiotica, ectosymbiotic with a Japanese gorgonacean octocoral, Melithaea flabellifera (Kükenthal) from Sagami Bay. Sci Rep Yokohama Natl Univ Sect II 39:1-11
Gunnill FC (1982) Macroalgae as habitat patch islands for Scutellidium lamellipes (Copepoda: Harpacticoida) and Ampithoe tea (Amphipoda: Gammaridae). Mar Biol 69: 103-116

Hamilton WD, May RM (1977) Dispersal in stable habitats. Nature 269:578-581

Hay ME, Fenical W (1988) Marine plant-herbivore interactions: the ecology of chemical defense. Annu Rev Ecol Syst 25:111-145

Hay ME, Duffy JE, Pfister CA (1987) Chemical defense against different marine herbivores: are amphipods insect equivalents? Ecology 68:1567-1580

Hay ME, Duffy JE, Fenical W (1990) Host-plant specialization decreases predation on a marine amphipod: an herbivore in plant's clothing. Ecology 71:733-743

Hewitt JE, Thrush SF, Cummings VJ, Pridmore RD (1996) Matching patterns with processes: predicting the effect of size and mobility on the spatial distributions of the bivalves Macomona liliana and Austrovenus stutchburyi. Mar Ecol Prog Ser 135:57-67

Highsmith RC (1985) Floating and algal rafting as potential dispersal mechanisms in brooding invertebrates. Mar Ecol Prog Ser 25:169-179

Howard RK (1985) Measurements of short-term turnover of epifauna within seagrass beds using an in situ staining method. Mar Ecol Prog Ser 22:163-168

Hughes RG (1988) Dispersal by benthic invertebrates: the in situ swimming behaviour of the amphipod Corophium volutator. J Mar Biol Assoc UK 68:565-579

Ingòlfsson A, Agnarsson I (2003) Amphipods and isopods in the rocky intertidal: dispersal and movements during high tide. Mar Biol 143:859-866

Johannesson K (1988) The paradox of Rockall: why is a brooding gastropod (Littorina saxatilis) more widespread than one having a planktonic larval dispersal stage (L. littorea)? Mar Biol 99:507-513

Kingsford MJ, Choat JH (1985) The fauna associated with drift algae captured with a plankton-mesh purse seine net. Limnol Oceanogr 30:618-630

Kumagai NH, Aoki MN (2003) Seasonal changes in the epifaunal community on the shallow-water gorgonian Melithaea flabellifera. J Mar Biol Assoc UK 83: 1221-1222

Kumagai NH, Shinagawa H, Sato T, Tsuchiya Y, Aoki MN (2004) Transplantation of gorgonian octocorals for in situ experimental manipulations. Benthos Res 59:11-19

Lawrie SM, Raffaelli DG (1998) In situ swimming behaviour of the amphipod Corophium volutator (Pallas). J Exp Mar Biol Ecol 224:237-251

MacKenzie BR, Miller TJ, Cyr S, Leggett WC (1994) Evidence for a dome-shaped relationship between turbulence and larval fish ingestion rates Limnol Oceanogr 39:1790-1799

Myers AA (1993) Dispersal and endemicity in gammaridean Amphipoda. J Nat Hist 27:901-908

Nelson WG (1979a) Experimental studies of selective predation on amphipods: consequences for amphipod distribution and abundance. J Exp Mar Biol Ecol 38:225-245

Nelson WG (1979b) An analysis of structural pattern in an eelgrass (Zostera marina L.) amphipod community. J Exp Mar Biol Ecol 39:231-264

Norkko A, Cummings VJ, Thrush SF, Hewitt JE, Hume T (2001) Local dispersal of juvenile bivalves: implications for sandflat ecology. Mar Ecol Prog Ser 212:131-144

Obara N (1937) Arrangement and movement of substratum in Shimoda Bay. J Mar Meteorol Soc 17:347-369

Palmer MA, Allan JD, Butman CA (1996) Dispersal as a regional process affecting the local dynamics of marine 
and stream benthic invertebrates. Trends Ecol Evol 11: 322-326

Pawlik JP (1992) Chemical ecology of the settlement of benthic marine invertebrates. Oceanogr Mar Biol Annu Rev 30:273-335

Poore AGB (2004) Spatial associations among algae affect host use in a herbivorous marine amphipod. Oecologia 140:104-112

Poore AGB, Steinberg PD (1999) Preference-performance relationships and effects of host plant choice in an herbivorous marine amphipod. Ecol Monogr 69:443-464

Reyns NB, Eggleston DB (2004) Environmentally-controlled, density-dependent secondary dispersal in a local estuarine crab population. Oecologia 140:280-288

Seuront L, Hwang JS, Tseng LC, Schmitt FG, Souissi S, Wong CK (2004) Individual variability in the swimming behavior of the sub-tropical copepod Oncaea venusta (Copepoda: Poecilostomatoida). Mar Ecol Prog Ser 283:199-217

Sokal RR, Rohlf FJ (1995) Biometry, 3rd edn. Freeman, New York

Stoner AW (1980) Abundance, reproductive seasonality and habitat preferences of amphipod crustaceans in seagrass meadows of Apalachee Bay, Florida. Contrib Mar Sci 23: 63-77

Sudo H, Azeta M (1992) Selective predation on mature male Byblis japonicus (Amphipoda: Gammaridea) by the barface

Editorial responsibility: Otto Kinne (Editor-in-Chief), Oldendorf/Luhe, Germany cardinalfish, Apogon semilineatus. Mar Biol 114:211-217

Tanaka MO, Leite FPP (2004) Distance effects on short-term recolonization of Sargassum stenophyllum by mobile epifauna, with an analysis of gammarid life habits. J Mar Biol Assoc UK 84:901-910

Turner SJ, Grant J, Pridmore RD, Hewitt JE, Wilkinson MR, Hume TM, Morrisey DJ (1997) Bedload and water-column transport and colonization processes by post-settlement benthic macrofauna: Does infaunal density matter? J Exp Mar Biol Ecol 216:51-75

Underwood AJ, Fairweather PG (1989) Supply-side ecology and benthic marine assemblages. Trends Ecol Evol 4: $16-20$

Utne ACW (1997) The effect of turbidity and illumination on the reaction distance and search time of the marine planktivore Gobiusculus flavescens. J Fish Biol 50:926-938

Van Dolah RF (1978) Factors regulating the distributions and population dynamics of the amphiopd Gammarus palustris in an intertidal salt marsh community. Ecol Monogr 48: 191-217

Virnstein RW, Curran MC (1986) Colonization of artificial seagrass versus time and distance from source. Mar Ecol Prog Ser 29:279-288

Yoshioka PM, Yoshioka BB (1991) A comparison of the survivorship and growth of shallow-water gorgonian species of Puerto Rico. Mar Ecol Prog Ser 69:253-260

Submitted: October 27, 2005; Accepted: February 2, 2006 Proofs received from author(s): August 3, 2006 